\title{
EFFECT OF DIFFERENT BEVERAGS ON COLOUR STABILITY OF DIFFERENT DENTURE BASE MATERIALS (A COMPARTIVE SPECTROMERTIC STUDY)
}

\author{
Kawkb Mohamed Eltamimi* and Sara Zaky Mohamed*
}

\begin{abstract}
Purpose: The purpose of this in vitro study was to investigate the effect of four solutions sterile water (control group), tea, coffee, cola on the color stability of different denture base materials (short cycle heat-polymerized PMMA, long cycle heat-polymerized PMMA, thermo plastic monomer free microcrystalline polymer and $3 \mathrm{~d}$ printed PEEK).
\end{abstract}

Material and methods: A total number of 160 specimens (forty specimens for each group) were constructed, specimens then were divided into four groups each group includes 10 from each denture base material (short cycle heat-polymerized PMMA, long cycle heat-polymerized PMMA, thermo plastic monomer free microcrystalline polymer, $3 \mathrm{~d}$ printed PEEK denture base material) were stored in each solution in room temperature in a dark environment. Colorimetric measurements were done before immersion and 6 weeks after immersion. Color differences among specimens immersed in water (control group), and staining solutions were evaluated over time. Data were statistically analyzed, with one-way analysis of variance (ANOVA) $(\alpha=0.05)$. ANOVA was followed by Duncan`s post hoc test to find which groups differed from each other.

Results: Result showed significant difference between groups before and after immersion in different beverages except for Cola solution in the PEEK at P-value 0.05, control group had no change in color before and after immersion in sterile water. Tea and cola showed the highest change in color with thermo plastic monomer free microcrystalline polymer.

KEYWORDS: Color stability, PEEK, Thermo plastic monomer free microcrystalline polymer, Acrylic resin and Spectrophotometer.

\section{INTRODUCTION}

Denture base color stability is a significant concern and obstacle for any dentist. Due to its strong physicochemical properties, good and easy processing and molding Polymethyl methacrylate is largely used as a denture base resin. Therefore, denture bases are subjected to various conditions leading to discoloration and staining by time, intrinsic and extrinsic factors plays a role in staining of denture base materials. ${ }^{(1)}$ Intrinsic factors such as

\footnotetext{
* Lecturer of Removable Prosthodontics, Faculty of Dentistry, Suez Canal University
} 
physicochemical properties including monomers, initiators, inhibitors, cross-linking agents, and intrinsic pigments. ${ }^{(2)}$ In addition, the degree polymerization of resins and degradation of chemical are often known as intrinsic factors affecting resin color stability. ${ }^{(3)}$ Extrinsic pigments derived from human diets, on the other hand adhere to and permeate the base resin to induce color changes. ${ }^{(4,5)}$ Signs of aging or material degradation and color instability is also a major factor in the need for of replacement of dentures. ${ }^{(6)}$

As a thermoplastic resin ,the microcrystalline polymer introduce many advantages over conventional denture base materials, including highly aesthetic, maximum strength and longevity, no volume shrinkage exceptional fit, minimal water absorption, lower residual monomer content. ${ }^{(7)}$

PEEK has good mechanical properties, excellent chemical-resistance, high-temperature stability, non-cytotoxic, tissue-compatible, electrically non-conductive, bio-inert and thermally insulating. Some other advantages of PEEK that make it suitable for dentistry are the poor electrical \& thermal conductivity with low friction. Parts made with PEEK have a tensile strength of 90-100 MPa and Young's modulus of $3.6 \mathrm{GPa}$ (bone-like elastic modulus).$^{(8)}$ There is a wide range of PEEK application in dentistry. For example, as frameworks for crowns and bridges, bases and clasps of dentures, partial crowns, implants, implant abutments and esthetic orthodontic wires. ${ }^{(9-13)}$

The science used to quantifying and understanding of human color is colorimetry. To determine color variations, two mainly used color systems are the Munsellcolor system and standard Commission Internationale de L' Eclairage (CIE Lab) color system. ${ }^{(14)}$ In terms of three coordinate values, Photometric and colorimetric instruments calculate color and express it in $\left(\mathrm{L}^{*}, \mathrm{a}^{*}, \mathrm{~b}^{*}\right)$, which locates the object's color within the CIELAB color space. The $\mathrm{L}^{*}$ coordinate reflects the brightness of an object, the $a^{*}$ value represents the red or green Chroma, and the $b^{*}$ value represents the yellow or blue Chroma. The color difference (E) of two objects can then be evaluated by comparing the differences between respective coordinate values for each object. The formula used for calculating color differences in this system is $\Delta \mathrm{E}=\left[\left(\mathrm{L}^{*}\right) 2+\left(\mathrm{a}^{*}\right) 2\right.$ $+\left(b^{*}\right)$ 2] $1 / 2$ where $L^{*}, a^{*}$, and $b^{*}$ are differences in color parameters for the two specimens measured for comparison. ${ }^{(15)}$ Spectrophotometer is one such evaluation system that is sensitive and accurate. ${ }^{(16)}$

The objectives of this study were to compare the color stability of four different denture base materials after immersion in different staining solution and the staining potential of the beverages most commonly used (tea, coffee and cola).

\section{MATERIAL AND METHODS}

160 Total number of disc shaped specimens (15x2mm.) were constructed, samples were divided equally into four groups randomly $(\mathrm{n}=10)$ according to storage media, coffee, tea, cola and distilled water (control group).

\section{Preparation of disc specimens}

\section{- Acrylic specimens}

Acrylic disc specimens were constructed and mixed conventionally according to manufacturing instructions (ACROSTONE, Egypt), packed in metal mold which was previously designed and tightly closed for specimen processing (hot water bath at 74 degree for nine hours for long cycle. For short cycle the flask was placed in hot water bath at 74 degree for 2 hours, then held at 100 degrees for one hour. (Figure $1 \mathrm{a}$ )

Using silicon carbide abrasive paper, the smoothing process was carries out then specimens where polished conventionally with pumice slurry mix and water. The discs were then kept in distilled water at room temperature for 24 hours to rid them off any residual monomer. 


\section{Polyether Ketone PEEK specimens}

For each printable PEEK disc(PEEK sheets, Petrorays Product Co., India)were additively manufactured via $\mathrm{F} / \mathrm{M}$ with printer HTRD 1.2 (Levamouis, Munich, Germany), all discs were printed with same parameters after printing samples were removed cooled at room temperature

\section{Thermo plastic monomer free microcrystalline polymer (KARADENT, TCS, INC,USA) specimens}

Spurred wax pattern was invested in vasalinized aluminum flask, teeming hard dental stone into upper flask chamber then injection of material (Sabliex, Microinjection machine, Argentina) after wax boiling, the cartridge of injected material was introduced into the heating cylinder.

After complete processing, flask was opened and specimens left to cool then finished and polished. (Figure $1 \mathrm{~b}$ )

- The color of specimens was assessed before the experiments using VITA Easy shade (VITA Zahnfabrik H. Rauter GmbH \& Co. KG). (Figure 1 c)

- Preparation of stored media

All medias were prepared by same operator at room temperature, coffee (Nescafe, Nestle Switzerland), Tea (Lipton, Unilever - Egypt), Cola
(The Coca-Cola company, Egypt) and distilled water as the control group

- Discs have been immersed in media for 6 weeks, with frequent stirring to prevent precipitation of media in the bottom, discs and media were kept in dry place and replaced on alternate days with fresh ones to prevent any microbial colonization and to maintain uniform concentration.

- After 6 weeks, discs are removed from medias and color measurement of each sample was preformed again with spectrophotometer, color changes $\Delta \mathrm{E}$ were calculated.

\section{Statistical analysis}

A normality test was done to check normal distribution of the samples, all data was calculated, tabulated and statistically analyzed using dependent T-test to compare between before and after solutions soaking at P-Value $\leq 0.05$.

One-way ANOVA was used to compare between the four solutions and also, the tested denture base materials under study. Duncan's post hoc test was performed for the evaluation of statistical significances among the treatments. Pvalue $\leq 0.05$ is considered be statistically significant. The computer program SPSS software for windows version 26.0 (Statistical Package for Social Science, Armonk, NY: IBM Corp) was used.

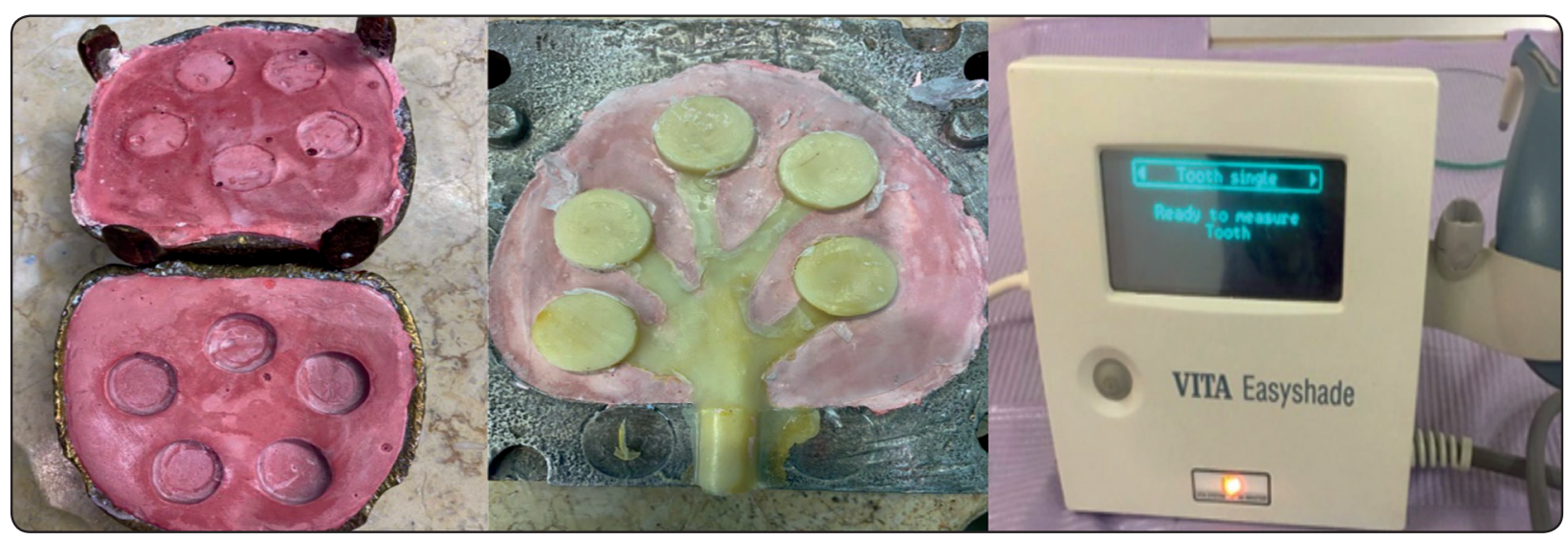

Fig. (1) a) fabrication of acrylic discs, flask with vasalinated hard stone. b) injected Karadent into flask. c) Vita easy shade used for measuring color changes. 


\section{RESULTS}

Each specimens where measured before and after immersion in different beverage, data was collected and tabulated as follow:

The difference between before and after immersion of denture base materials in different solutions for the short, long cycle PMMA, karadent and PEEK were illustrated in the table (1) figure
(2), With regard to Tea, Coffee, and Cola solutions, the results showed a significant difference between before and after immersion of short, long cycle PMMA, karadent and PEEK in the color change, except for PEEK in the Cola solution at P-value 0.05 . Whereas the color degree of samples did not differ by soaking in the water for all tested denture base materials.

TABLE (1) t-test for comparing the difference between different denture base materials before and after immersion in solutions.

\begin{tabular}{|c|c|c|c|c|c|c|}
\hline \multirow{2}{*}{\multicolumn{2}{|c|}{ Solutions }} & \multicolumn{2}{|c|}{ Mean \pm SD } & \multirow{3}{*}{$\begin{array}{l}\text { T-test } \\
-4.131\end{array}$} & \multirow{3}{*}{$\begin{array}{c}\text { Sig } \\
0.045 *\end{array}$} & \multirow{3}{*}{$\begin{array}{c}\mathbf{r} \\
0.997\end{array}$} \\
\hline & & \multirow{2}{*}{$\begin{array}{c}\text { Before } \\
115.77 \pm 2.04 \\
\end{array}$} & \multirow{2}{*}{$\begin{array}{c}\text { After } \\
117.30 \pm 1.41 \\
\end{array}$} & & & \\
\hline \multirow{4}{*}{ Tea } & Short cycle & & & & & \\
\hline & Long cycle & $114.17 \pm 2.46$ & $116.37 \pm 1.25$ & -2.93 & $0.045 *$ & 0.962 \\
\hline & Karadent & $107.93 \pm 1.89$ & $96.00 \pm 2.81$ & 10.28 & $0.009 *$ & 0.698 \\
\hline & PEEK & $36.00 \pm 2.75$ & $32.67 \pm 1.01$ & 2.021 & $0.018 *$ & 0.89 \\
\hline \multirow{4}{*}{ Coffee } & Short cycle & $113.20 \pm 0.82$ & $116.47 \pm 0.70$ & -5.953 & $0.027 *$ & 0.226 \\
\hline & Long cycle & $117.23 \pm 3.00$ & $119.57 \pm 2.33$ & -6.07 & $0.040 *$ & 0.98 \\
\hline & Karadent & $108.17 \pm 1.40$ & $111.83 \pm 1.36$ & -2.73 & $0.021 *$ & -0.390 \\
\hline & PEEK & $36.13 \pm 1.49$ & $29.47 \pm 1.86$ & 1.794 & $0.043^{*}$ & 0.86 \\
\hline \multirow{4}{*}{ Cola } & Short cycle & $114.70 \pm 1.94$ & $117.30 \pm 2.55$ & -5.166 & $0.035^{*}$ & 0.960 \\
\hline & Long cycle & $117.60 \pm 1.17$ & $120.10 \pm 1.16$ & -3.613 & $0.020 *$ & 0.066 \\
\hline & Karadent & $107.30 \pm 1.04$ & $112.17 \pm 0.21$ & -9.911 & $0.010^{*}$ & 0.943 \\
\hline & PEEK & $32.93 \pm 1.02$ & $33.07 \pm 1.98$ & -0.045 & 0.968 & 0.169 \\
\hline \multirow{4}{*}{ Water } & Short cycle & $117.97 \pm 1.26$ & $118.37 \pm 1.20$ & -6.928 & 0.075 & 0.998 \\
\hline & Long cycle & $115.10 \pm 0.95$ & $115.43 \pm 0.94$ & -2.29 & 0.149 & 0.96 \\
\hline & Karadent & $108.13 \pm 1.32$ & $107.97 \pm 1.57$ & 0.714 & 0.549 & 0.975 \\
\hline & PEEK & $36.23 \pm 3.59$ & $36.13 \pm 3.57$ & 0.23 & 0.820 & 0.99 \\
\hline
\end{tabular}

* means significant difference at the same column at P-value $\leq 0.05$

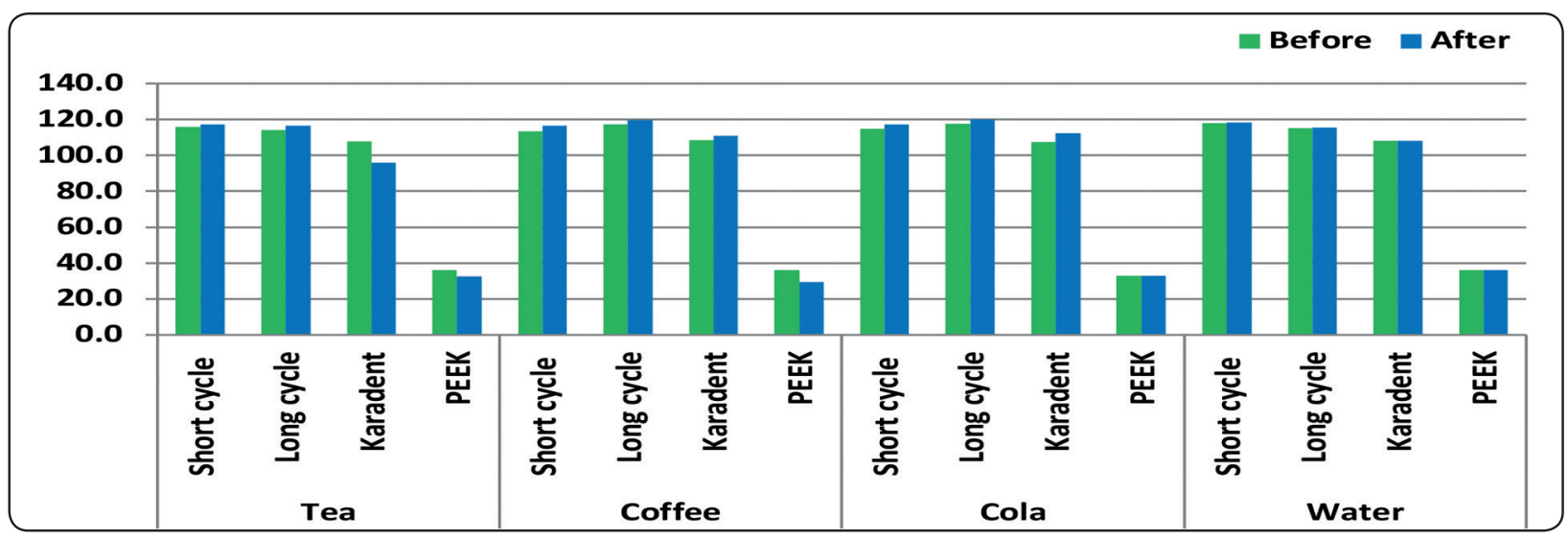

Fig. (2) The difference between different denture base materials before and after immersion in solutions. 
The results in table (2) and figure (3) Showed significant difference between tea, coffee, Cola and water in $\Delta \mathrm{E}$ for all tested denture base materials. Concerning to short cycle, the high value was recorded in coffee soaking, followed by cola solution. For long cycle, the $\Delta \mathrm{E}$ was almost very similar in the tea, coffee and cola, but they were more significantly visible compared to the water solution. With regard to Karadent, the $\Delta \mathrm{E}$ was significantly high in the tea solution compared with others followed by Cola. Finally for the PEEk, the tea and the coffee gave almost similar $\Delta \mathrm{E}$ also; cola and water didn't differ in color degrees.

The results in table (3) Showed significant difference between short, long cycle PMMA, Karadent and PEEK for tea, coffee, cola and water. The high $\Delta \mathrm{E}$ of tea and Cola solutions were recorded in Karadent and the high value of coffee was recorded in the short cycle followed by PEEK. On the other side the $\Delta \mathrm{E}$ for all solution didn` $\mathrm{t}$ differ in for groups.
TABLE (2) Changes in $\Delta \mathrm{E}$ values caused by each solution in tested denture base materials.

\begin{tabular}{|l|c|c|c|c|}
\hline Solution & $\begin{array}{c}\text { Short } \\
\text { cycle }\end{array}$ & $\begin{array}{c}\text { Long } \\
\text { cycle }\end{array}$ & Karadent & PEEK \\
\hline Tea & $1.53^{\mathrm{c}} \pm 0.64$ & $2.20^{\mathrm{a}} \pm 1.30$ & $11.93^{\mathrm{a}} \pm 2.01$ & $3.33^{\mathrm{a}} \pm 1.86$ \\
\hline Coffee & $3.26^{\mathrm{a}} \pm 0.95$ & $2.33^{\mathrm{a}} \pm 0.67$ & $2.56^{\mathrm{c}} \pm 0.86$ & $3.20^{\mathrm{a}} \pm 1.60$ \\
\hline Cola & $2.60^{\mathrm{b}} \pm 0.87$ & $2.53^{\mathrm{a}} \pm 1.06$ & $4.86^{\mathrm{b}} \pm 0.45$ & $0.16^{\mathrm{b}} \pm 0.01$ \\
\hline Water & $0.40^{\mathrm{d}} \pm 0.1$ & $0.33^{\mathrm{b}} \pm 0.20$ & $0.16^{\mathrm{d}} \pm 0.40$ & $0.10^{\mathrm{b}} \pm 0.10$ \\
\hline P- value & $\mathbf{0 . 0 1}^{*}$ & $\mathbf{0 . 0 4}^{*}$ & $\mathbf{0 . 0 0}^{*}$ & $\mathbf{0 . 0 1}^{*}$ \\
\hline
\end{tabular}

*;a,b,c; means significant difference at the same column at $P$-value $\leq 0.05$

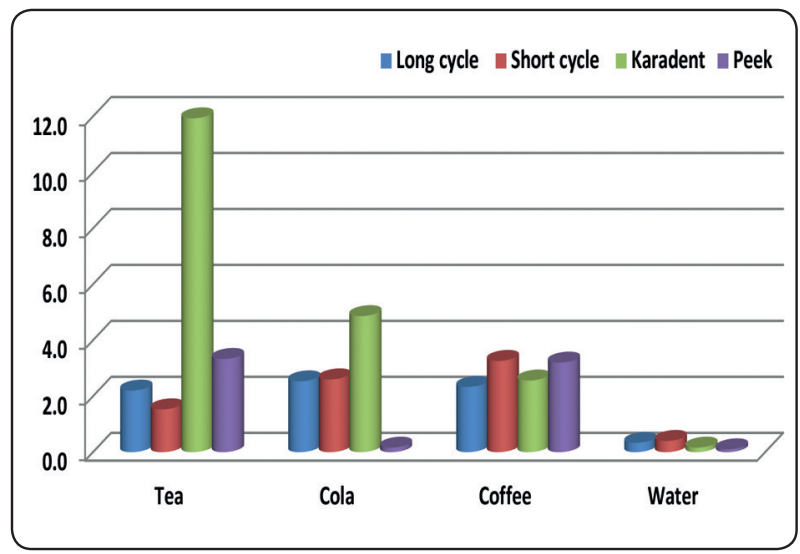

Fig. (3). Changes in $\Delta \mathrm{E}$ values caused by each solution in tested denture base materials.

TABLE (3) Changes in $\triangle E$ values in each tested denture base material caused by soaking solution.

\begin{tabular}{|l|c|c|c|c|c|}
\hline & Short cycle & Long cycle & Karadent & PEEK & P value \\
\hline Tea & $1.53^{\mathrm{c}} \pm 0.64$ & $2.20^{\mathrm{bc}} \pm 1.30$ & $11.93^{\mathrm{a}} \pm 2.01$ & $3.33^{\mathrm{b}} \pm 1.86$ & $0.00^{*}$ \\
\hline Coffee & $3.26^{\mathrm{a}} \pm 0.95$ & $2.33^{\mathrm{a}} \pm 0.67$ & $2.56^{\mathrm{c}} \pm 0.86$ & $3.20^{\mathrm{a}} \pm 1.60$ & $0.03^{*}$ \\
\hline Cola & $2.60^{\mathrm{b}} \pm 0.87$ & $2.53^{\mathrm{b}} \pm 1.06$ & $4.86^{\mathrm{a}} \pm 0.45$ & $0.16^{\mathrm{c}} \pm 0.01$ & $0.02^{*}$ \\
\hline Water & $0.40^{\mathrm{a}} \pm 0.1$ & $0.33^{\mathrm{a}} \pm 0.20$ & $0.16^{\mathrm{a}} \pm 0.40$ & $0.10^{\mathrm{a}} \pm 0.10$ & 0.60 \\
\hline
\end{tabular}

$a, b, c$; means significant difference at the same raw at $P$-value $\leq 0.05$ 


\section{DISCUSSION}

Denture base material used for the fabrication of dentures is present in an atmosphere having variations in oral temperature, the $\mathrm{pH}$ of saliva, and their component and must be in contact with several foods, drinks and beverage taken at various temperatures rendering them susceptible to changes in their physical structure and appearance due to the absorption of different contaminants. ${ }^{(17)}$

Dental prostheses discoloration varies according to type of resin matrix, percentage and filler size incorporated fillers distribution, composition and polymerization mode ${ }^{(18)}$ age, restoration processing mode, also extrinsic factors affect the color stability of dental prosthesis such as, staining from adherent or penetrated by food colorants, such as caffeine, nicotine, anthocyanidins and tannins, in beverages, or mouth rinses and smoking. ${ }^{(19)}$ All these necessitate the application of effective cleaning methods.

In this research, PEEK resins were compared with a conventional heat polymerized resin (short cycle and long cycle processed), and Karadent, as storage media used was coke, Tea and coffee because basically that these beverages are frequently consumed by people in Egypt. After examination, the denture base materials showed significantly different discoloration after storage in various media.

In dentistry a color change that is more than detectable $(\Delta \mathrm{E}>1.0)$ is considered acceptable up to a $\Delta E$ value of 3,3 ; above this value it is considered unacceptable. (20) Only specimens of Karadent denture base material, stored in tea, coke were clinically unacceptable after the 45 days $(\Delta \mathrm{E}$ was 11.93 and 4.86 respectively).

Specimens immersed in tea showed the most color changes which is agreed with studies reported that the tea produced a yellow- brown stain while coffee stain was yellowish. The tea discoloration was primarily due to surface adsorption of polar colorants at the surface. ${ }^{(21)}$
Other studies, however have found that coffee was more chromogenic discoloration than tea. Both surface absorption and adsorption of colorants are responsible for the discoloration of coffee. Deposits of small coffee particles into denture base materials pits. Less polar colorants and water soluble polyphenols in coffee for example tannin, caffeine and caffeic acid may have penetrated deep into the material, probably because such colorants would be more compatible with polymer matrices. ${ }^{(22,23)}$

Previous studies of coffee and tea staining of denture base products have shown that coffee immersed samples stained more because their brown pigmentation has lower polarity than that of green tea. ${ }^{(24)}$ Other research noted that the change in color caused by coffee is more severe because it includes complex interactions between adsorption and absorption, encouraged by the affinity between colors and materials, while the change in color caused by tea is mainly due to adsorption. ${ }^{(25)}$ In accordance with this finding, all samples immersed in coffee showed more intense changes in color than those immersed in cola. ${ }^{(21)}$

Studies stated that Acrylic resins are susceptible to sorption owing to the method of absorption and adsorption of various colors. Several studies in the past years have shown the difference in color stability between different brands of heat-cured resins. ${ }^{(26)}$

Acrylic resin is an organic material and its translucency and color are likely to deteriorate due to the adhesion of colorants to the surface pellicle layer forming on the denture base material when they come into contact with different compounds in food products and beverages. ${ }^{27,28)}$

Karadent denture base material showed the most color instability among the groups, there is no enough studies about the material properties, instability of color may be due to increased number of pits leading to more adsorption of the beverage inside the material. 
PEEK specimens showed the lowest color instability among the groups this agreed with the studies stated that PEEK has least water absorption, solubility and HM values as compared to PMMA-based and composite resin materials. During a storage period of 180 days in saliva and distilled water, water absorption was independent of the storage medium, but showed dependency on storage duration and material properties. ${ }^{(29)}$ The findings can be explained by the fact that a higher, in conjunction with a lower filler particles content, a higher volume of resin matrix results in higher water absorption. ${ }^{(30)}$

Other researches stated that PEEK showed the significantly $(\mathrm{p}<0.001)$ lowest discoloration of all coloring media after a one-week storage relative to PMMA and COMP. PEEK starts with higher L values and a lower tendency to discoloration than COMP and PMMA. ${ }^{(31)}$

\section{CONCLUSION}

Within the limitations of this in vitro study, the following conclusions could be drawn: The color stability of PEEK denture base resins is better than that of some other kinds of denture base resins (PMMA and Karadent). All the changes in the color values of the groups. All beverages used in the study had an effect on color change. Karadent to be used as a denture base material need further investigations and studies.

\section{REFERENCES}

1. Barão V, Ogawa E, Moreno A, Mesquita M, Wee A, Assunção W. Long-term clinical evaluation of the color stability and stainability of acrylic resin denture teeth. J Prosthet Dent. 2015; 113(6):628-35.

2. Bonatti M, Cunha T, Regis R, Silva-Lovato C, Paranhos $\mathrm{H}$, de $\mathrm{S}$ ouza $\mathrm{R}$. The effect of polymerization cycles on color stability of microwave processed denture base resin. J Prosthodont. 2009; 18(5):432-7.

3. May K, Shotwell J, Koran A 3rd, Wang RF. Color stability: denture base resins processed with the microwave method. J Prosthet Dent 1996; 76:447-456.
4. Ergüiü Z, Türkün L, Aladag A. Color stability of nanocomposites polished with one-step systems. Oper Dent. 2008; 33(4):413-20.

5. Ayaz E, Altintas S, Turgut S. Effects of cigarette smoke and denture cleaners on the surface roughness and color stability of different denture teeth. J Prosthet Dent. 2014; 112(2):241-8.

6. Imirzalioglu P, Karacaer O, Yilmaz B, Ozmen Msc I. Color stability of denture acrylic resins and a soft lining material against tea, coffee, and nicotine. J Prosthodont. 2010; 19(2):118-24.

7. Abd El Hameed $\mathrm{H}$ and Husseiny E. Bond strength of hard and soft relining materials to thermoplastic monomer free microcrystalline polymer (in-vitro comparative study). EDJ.2018; 64(4):3559-3566.

8. Rosentritt M, Preis V, Behr M, Sereno N, Kolbeck C. Shear bond strength between veneering composite and PEEK after different surface modifications. Clin Oral Investig. 2015; 19(3): 739-744.

9. Zoidis P, Bakiri E, Polyzois G. Using modified polyetherether ketone (PEEK) as an alternative material for endocrown restorations: a short-term clinical report. J Prosthet Dent. 2017;117(3):335-339.

10. Tekin S, Cangül S, Adıgüzel Ö, De ger Y. Areas for use of PEEK material in dentistry. IDR 2018; 8(2):84-92.

11. Park C, Jun DJ, Park SW, Lim HP. Use of polyaryletherketone(PAEK) based polymer for implantsupported telescopic overdenture: a case report. J Adv Prosthodont. 2017; 9(1):74-76.

12. Ali MZ, Baker S, Martin N. A Pilot Randomized Controlled Crossover Trial Comparing Early OHRQoL Outcomes of Cobalt-Chromium Versus PEEK Removable Partial Denture Framework. Int J Prothodont. 2020; 33(4): 386-392.

13. Muhsin S, Hatton P, Johnson A, Sereno N and Wood D. Determination of Polyetheretherketone (PEEK) mechanical properties as a denture material. Saudi Dent J. 2019;31(3): 382-391.

14. Kazuki S, Yoshiyuki K, Hideo M, and Naomi T. In vivo quantitative evaluation of tooth color with hand-held colorimeter and custom template. J Prosthet Dent. 2004; 91(4): 389-391.

15. Berns R, Bilmeyer F, Saltzman M. Principles of color technology (ed 3). New York,John Wily, 2000, p 71-74. 
16. Um C and Ruyter I. Staining of resin-based veneering materials with coffee and tea. Quintessence Int. 1991; 22(5): 377-86.

17. Hollis S, Eisenbeisz E, Versluis A. Color stability of denture resins after staining and exposure to cleansing agents. J Prosthet Dent. 2015;114(5):709-14.

18. Kumari RV, Nagaraj H, Siddaraju K, Poluri RK. Evaluation of the Effect of Surface Polishing, Oral Beverages and Food Colorants on Color Stability and Surface Roughness of Nanocomposite Resins. J Int Oral Health. 2015;7(7):63-70.

19. Liebermann A, Wimmer T, Schmidlin P. Physico-mechanical characterization of polyetheretherketone and current esthetic dental CAD/CAM polymers after aging in different storage media. J prosth dent.2016; 115(3):321-8.

20. Zuo W, Feng D, Song A, Gong H, Zhu S. Effects of organic-inorganic hybrid coating on the color stability of denture base resins. J Prosthet Dent. 2016; 115(1):103-8.

21. Joiner A, Muller D, Elofsson U M, Malmsten M, Arnebrant TH. Adsorption from black tea and red wine onto in vitro salivary pellicles studied by ellipsometry. Eur J Oral Sci. 2003; 111(5):417-22.

22. Yu-lin Lai, Ho-fu Lui, Shyh-yuan Lee. In vitro color stability, stain resistance, and water sorption of four removable gingival flange materials. J Prosthet Dent. 2003; 90(3): 293-300.

23. Scotti R, Mascellani SC, Forniti F. The in vitro color stability of acrylic resins for provisional restorations. Int $\mathrm{J}$ Prosthodont. 1997; 10 (2): 164-8.
24. Sepúlveda-Navarro W, Arana-Correa B, Borges C, Jorge J, Urban V, Campanha N. Color stability of resins and nylon as denture base material in beverages. J Prosthodont. 2011; $20(8): 632-638$.

25. Bohra P, Ganesh P, Reddy M, Ebenezar A, Sivakumar G. Colour stability of heat and cold cure acrylic resins. J Clin Diagn Res. 2015; 9(1):12-15.

26. Wozniak W, Muller T, Silverman R, Moser J. Photographic assessment of colour changes in cold and heat-cure resins. J Oral Rehabil. 1981; 8(4):333-339.

27. Watts D, Bertenshaw B, Jugdev, J. PH and time-dependence of surface degradation in a compomer biomaterial. $\mathrm{J}$ Dent Res.1995; 74:912.

28. Mousavi S, Narimani S, Hekmatfar S, Jafari K. Colour stability of various types of acrylic teeth exposed to coffee, tea and cola. J Dent Biomater. 2016; 3(4):335-340.

29. Gupta G, Gupta T. Evaluation of the effect of various beverages and food material on the color stability of provisional materials - An in vitro study. J Conserv Dent. 2011; 14(3): 287-292.

30. Anfe T, Agra C, Vieira G. Evaluation of sorption, solubility and staining of universal and silorane resin based composites. Eur J Prosthodont Restor Dent. 2011; 19(4):151-4.

31. Alexakou E, Damanaki M, Zoidis P, Bakiri E, Mouzis N, Smidt G, Kourtis S. PEEK High Performance Polymers: A Review of Properties and Clinical Applications in Prosthodontics and Restorative Dentistry. Eur J Prosthodont Restor Dent. 2019; 27(3):113-121. 